\title{
Multi Objective Dynamic Economic Dispatch with Cubic Cost Functions
}

\author{
Moses Peter Musau, Nicodemus Odero Abungu, Cyrus Wabuge Wekesa \\ Department of Electrical and Information Engineering, School of Engineering, The University of Nairobi, Nairobi, Kenya
}

Email address:

pemosmusa@gmail.com (M. P. Musau), abunguodero@gmail.com (N. O. Abungu), cyrus_wekesa@yahoo.com (C. W. Wekesa)

\section{To cite this article:}

Moses Peter Musau, Nicodemus Odero Abungu, Cyrus Wabuge Wekesa. Multi Objective Dynamic Economic Dispatch with Cubic Cost Functions. International Journal of Energy and Power Engineering. Vol. 4, No. 3, 2015, pp. 153-167. doi: 10.11648/j.ijepe.20150403.14

\begin{abstract}
The formulation and solution of the Dynamic Economic Dispatch (DED) problem is one of the key disciplines in modern power system operation, planning, operation and control. Past researches have considered DED on Quadratic Cost Functions (QCF), with only few works considering higher order cost functions which are more accurate. The Static Economic Dispatch (SED) has been widely tackled in past researches, however, it is the DED problem that represents a real life power system. There is need to review this problem and establish a more practical formulation of the same taking into consideration all the objectives and constraints possible. The methods used in the solution of DED problem have evolved from the traditional deterministic ones, to the pure heuristic, and finally to the state of the heart hybrids. The hybrids methods have been developed to exalt the strengths and improve the weaknesses of the base method. Such optimisation methods need to be reviewed and classified. This paper will do an in depth review of the DED problem on both quadratic and cubic cost functions. Further it will provide a detailed classification of the methods used to solve the problem as its complexity increases. Consequently, three method Hybrids is the way go as far as the solution of the cubic Multi Objective DED (MODED) with five objectives is concerned.
\end{abstract}

Keywords: Cubic Cost Functions (CCF), Dynamic Economic Dispatch (DED), Hybrid Methods, Multi Objective DED (MODED)

\section{Introduction}

The fuel cost in in existing textbooks, for example Optimization of Power System Operation [1] is generally assumed to be a smooth Static ED (SED) modeled as a Quadratic Cost Function(QCF).According to Jizhong Zhu, pp85-88, (2006) [1], this definition however makes many assumptions which are impractical to real systems. These assumptions include ignoring emissions, uncertainties, reactive power dispatch, ramp rates, valve points and integration of Renewable Energy (RE) generators. These assumptions are impractical in the real time power system and can no longer be ignored. Consideration of such assumptions in ED formulation leads to the DED formulation and solution.

DED optimization problem is one of the most important issues which must be taken into consideration in power systems planning and operation. DED is aimed at planning the power output for each devoted generator unit in such a way that the operating cost is minimized and simultaneously, matching real and reactive load demand, power operating limits and above all maintaining the system stability. Further, the security challenges and power trade issues need to be addressed in such a formulation. Based on convention, electrical power systems are operated based on minimizing operational cost while maintaining all the system constraints in place.

The integration of renewable energy into the grid and the need to account for the emission and transmission (real and reactive) losses in a more accurate sense has greatly affected the way in which the DED problem is formulated and solved. This is due to the use of different generators which utilize various fuels and the fact that their real and reactive power outputs are not deterministic but stochastic in such a case. Thus, there has been a desperate need to review the formulation and solution of the existing DED problem.

The Thermal, Renewable Energy (RE), Emissions and Transmission Loss cost functions when considered 
individually, results in a Single Objective DED (SODED). The SODED has been considered on a Quadratic Cost Function which is less accurate. Where more than two objectives are taken into consideration, a MODED problem results. In most researches, the thermal cost functions has been taken as the base cost function then the other functions and the corresponding constraints have been added depending on the interest of the researcher. However there is need to consider all these objectives and constraints simultaneously since they do affect the modern power system in such a practical manner. The Multi Objective DED(MODED) which is well suited for the modern smart grid need to be revisited to include wind ,solar, emission and transmission line losses in a more accurate scenario in which the five main objectives are handled simultaneously in a fully constrained environment.

Dealing with multiple and conflicting objectives in optimization engineering has always been a challenging undertaking. Many practical applications in optimization often involve many goals to be satisfied simultaneously. In power system planning, operation and control, MODED is a good example of such problems. As the MODED gets more complex, improved and higher order cost functions will continue to replace the Quadratic ones. This is because the higher order cost functions have proved to be more accurate and realistic than the traditional Quadratic ones. In addition, Hybrid methods which do accommodate the uncertain RE will replace the static ones which are restricted to one or two objectives. Also, the existing hybrids must also be tested on higher order cost functions for the MODED with more objectives. Further, three and four method hybrids will be embraced for more accurate realistic results.

Most of the existing security, reactive power and multi area problems of the economic dispatch has been considered in a static environment and using the classical methods. There is need to reconsider these problems in the MODED with the stochastic RE. This will lead to improved ED, increased system security, advanced voltage profile and better trade on electrical power.

This research paper aims at addressing the MODED problem by providing a detailed review of the existing DED works in terms of the problem formulation and the solution methods used. The paper has been divided into six main sections. There is an introduction to power system operation and planning, DED overview, MODED review, formulation of MODED and the existing sub problems, a classification of DED optimization methods and the review conclusion.

\section{Modern Power System Operation and Planning}

Power system operation and control problem include the Unit Commitment (UC), Optimal Power Flow (OPF), SED, Hydro-Thermal Scheduling (HTS), and DED which are integrated to each other. According to a review of the Science Direct databases, there is not as many studies of the DED problem and it has not been as thoroughly investigated as other electric power system optimization areas of study [3].This is evident in Table 1. Similar to most of the realworld complex engineering optimization problems, the nonlinear and non-convex characteristics of the cubic cost functions $(\mathrm{CCF})$ are more prevalent in the DED problem more so with the increasing number of objectives and constraints.

Survey of published works dealing with these optimization problems include N.P. Padhy,2004 [2] for the UC, J.A. Momoh et al ,1999 [4] and M.R. Al Rashid and M.E. ElHawary,2009 [5] for the OPF and A. Mahor et al ,2009 [6] ,H. Altun and T. Yalcinoz ,2008 [7] for the SED.

Table 1. Power System Planning, Operation and Control [3].

\begin{tabular}{ll}
\hline Optimization Area & \% Publications \\
\hline SED & 21 \\
DED & 4 \\
OPF & 27 \\
HTS & 14 \\
\hline
\end{tabular}

\section{Dynamic Economic Dispatch (DED)}

Dynamic Economic Dispatch (DED) involves the formulation and solution of the thermal ED such that the ramp rates, valve points and all the possible constraints are accounted for. As evident in Table 1, the DED occupies a prominent place in a power system's planning, operation and control. The goal of DED is to determine the optimal power outputs of online generating units in order to meet the load demand subject to satisfying various operational equality and inequality constraints over finite dispatch periods. In practice, there are SED and DED problems where the latter considers additional practical constraints. Early research works addressing this aspect were published by T.E.Bechert and H.G. Kwatny, 1972 [8] and T.E. Bechert and Nanming Chen, 1977 [9].The DED problem has not been addressed and researched as thoroughly as other power optimization problems. Xia et al, 2010, [10] offered a review of DED highlighting the problem constraints and some available solution methods. The work presented in this research paper is different in that it categorizes earlier work based on the optimization algorithms, number of objective functions involved, number and type of constraints, type of coast function and published works with RE cost functions. Figure 1 illustrates annual published research on DED according to a review of the Science Direct databases [3].As shown in the figure, the number of publications on DED is on increase. This signifies the undeniable importance of investigating the DED problem.

From the published works sampled, the number of works integrating the Renewable Energy (RE) into the DED problem have been increasing significantly. This means that the inclusion of the RE into the ED problem can no longer be ignored since the security, reactive power and multi area aspects of the power system are affected. This is as shown in the Figure 2. 


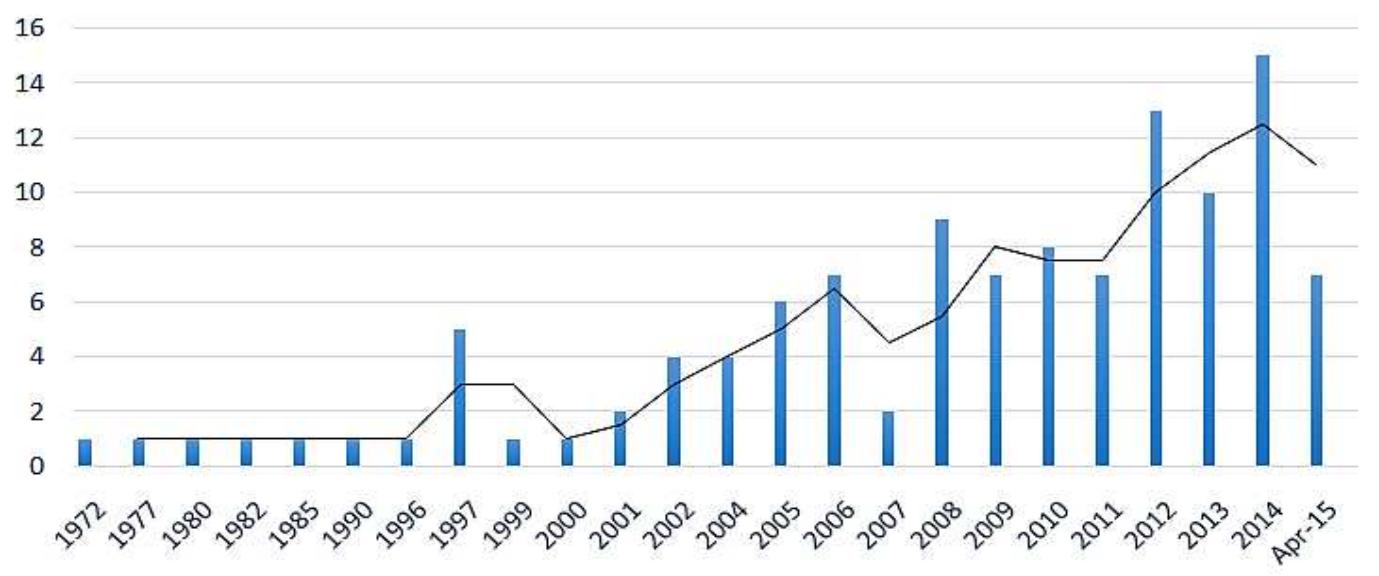

NO OF DED PUBLICATIONS - 2 per. Mov. Avg. (NO OF DED PUBLICATIONS)

Figure 1. DED Publications Since 1970s[3].

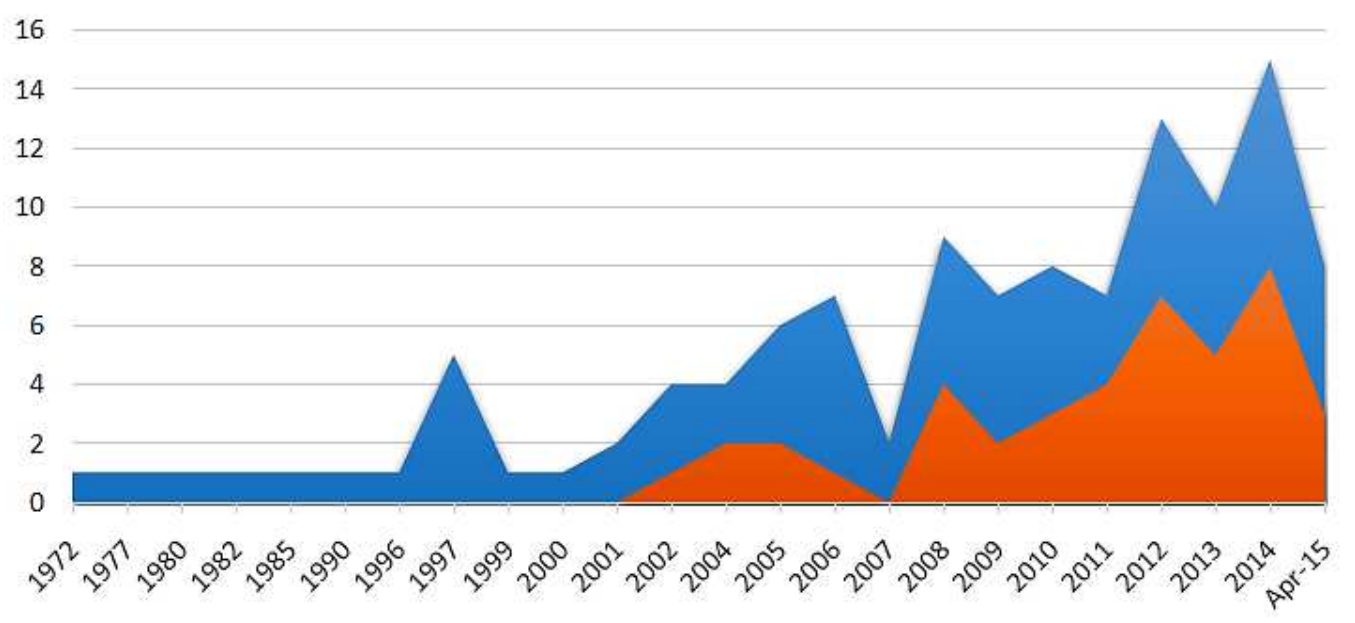

- Total DED Publications a Publications with RE

Figure 2. DED Publications with RE Since 1970s[3].

\section{MODED Review}

The history of the MODED problem dates back to early 2000 when transmission losses were considered as a cost function other than a constraint leading to the formulation of the first 2-objective MODED[12]

Table 2.2 summarizes the MODED problem so far.The summary includes the number and types of objectives, the type of method used and the number of constraints. From the table, it is clear that there is need to solve the MODED with all the five major objectives considered simultaneously on cubic cost functions. Further the problem need to be constrained further for more realistic results.

Table 2. MODED Problem with Quadratic Cost Function (QCF).

\begin{tabular}{|c|c|c|c|c|c|}
\hline Researcher & $\mathbf{n}$ & Objectives & Solution Method(s) & Con & Type \\
\hline Faisal .A. Mohamed ,2009[11] & 4 & T,W,S,E & Non Linear Constrained Method (NLCM) & 2 & $\mathrm{Q}$ \\
\hline M.A Abibo, 2003 [12] & 2 & $\mathrm{~T}, \mathrm{TL}$ & Strength Pareto Evolutionary Algorithm (SPEA) & 3 & Q \\
\hline Zhao Bo and Cao Yi-Jia,2005[13] & 3 & T,E,TL & Multi Objective Particle Swarm Optimization (MOPSO) & 5 & Q \\
\hline M.A Abibo, 2006[14] & 2 & $\mathrm{~T}, \mathrm{TL}$ & SPEA and Strength Pareto Genetic Algorithm (SPGA) & 4 & Q \\
\hline $\begin{array}{l}\text { M. Basu, } 2006 \text { [15], Amitah } \\
\text { Mahor ,2009[16], }\end{array}$ & 2 & $\begin{array}{l}\mathrm{T} \\
\mathrm{E}\end{array}$ & Particle Swarm Optimization (PSO) & 3 & Q \\
\hline M .Basu, 2007 [17] & 2 & $\mathrm{~T}, \mathrm{E}$ & Evolutionary Programming (EP) and Fuzzy Logic (FL)-(EP-FL) & 4 & Q \\
\hline C .Chen, 2007 [18] & 2 & $\mathrm{~T}, \mathrm{~W}$ & Simulated Annealing (SA) and Direct Search Method (DSM)-(SA-DSM) & 4 & Q \\
\hline M.Basu, 2008 [19] & 2 & $\mathrm{~T}, \mathrm{E}$ & Elitist Non-Dominated Sorting Genetic Algorithm-II (ENSGA-II) & 3 & Q \\
\hline R.P Brent, 2010 [20] & 2 & T,E & Preference-based Non-Dominated Sorting Genetic Algorithm (PNDSGA) & 5 & $\mathrm{Q}$ \\
\hline
\end{tabular}




\begin{tabular}{|c|c|c|c|c|c|}
\hline Researcher & $\mathbf{n}$ & Objectives & Solution Method(s) & Con & Type \\
\hline Zwe-Lee Gaing et al ,2009 [21] & & $\mathrm{T}, \mathrm{E}$ & Bacterial Foraging(BF)-PSO-Differential Evolution-(DE) (BF-PSO-DE) & 4 & Q \\
\hline Alsumait et al, 2010 [22] & 2 & $\mathrm{~T}, \mathrm{E}$ & Pattern Search (PS) & 3 & Q \\
\hline S.Subramanial et al, 2010 [23] & 3 & $\mathrm{~T}, \mathrm{E}, \mathrm{TL}$ & Sequential Approach with Matrix Framework (SAMF) & 6 & Q \\
\hline Chunghun et al,2013 [24] & 3 & $\mathrm{~T}, \mathrm{~W}, \mathrm{~S}$ & Model Predictive Control (MPC) & 5 & Q \\
\hline Haiwang Zhong et al,2013[25] & 2 & $\mathrm{~T}, \mathrm{TL}$ & Penalty-Based Algorithm (PBA) & 4 & Q \\
\hline Azza A. ElDesouky, 2013 [26] & 4 & $\mathrm{~T}, \mathrm{~W}, \mathrm{~S}, \mathrm{E}$ & Weighted Aggregation (WA) and PSO(WAPSO) & 7 & $\mathrm{Q}$ \\
\hline Bakirtzis et al ,2014 [27] & 2 & $\mathrm{~T}, \mathrm{~W}$ & Variable Time Resolution (VTR) and Scheduling Horizon (SH)-(VTRSH) & 4 & Q \\
\hline $\begin{array}{l}\text { Soubache ID and Sudhakara } \\
\text { Reddy,2014[28] }\end{array}$ & 2 & $\mathrm{~T}, \mathrm{E}$ & Multi Objective Computer Programming Based Method(MOCPBM) & 5 & Q \\
\hline
\end{tabular}

Key

Q-Quadratic Function,

C-Cubic Function,

n- Number of objective

T-Thermal cost objective function

W-Wind, cost objective function

S-Solar cost objective function

E-Emissions cost objective function

TL-Transmission Losses)

Con-Number of constraints

ED with cubic cost functions has been studied in the recent past . According Z.X Liang and J.D Glover ,1991[29], a very crucial issue in DED studies is to determine the order and approximate the coefficients of the polynomial used to model the cost function. This helps in reducing the error between the approximated polynomial along with its coefficients and the actual operating cost. According to Z.X Liang and J.D Glover,1992 [30] and A.Jiang and S.Ertem,1995 [31] to obtain accurate ED results, a third order polynomial is realistic in modelling the operating cost for a nonmonotonically increasing cost curve. DED works using cubic cost functions include Bharathkumar S et al, 2013[32], Hari M.D et al, 2014[33], Deepak Mishra et al, 2006[34], and
N.A.Amoli et al, 20 12[35]. Krishnamurthy, 2012 [36] used the static cubic function of the emissions dispatch in the Multi Objective Static ED(MOSED) using the Lagrange Method(LM).This provided better results as compared to the quadratic functions. In all these studies, the cubic cost function provided more accurate and practical results as compared to lower order cost functions. A summary of ED works using cubic cost functions is provided in Table 3.From the table, it is clear that cubic renewable and transmission losses cost functions have not been considered. Further, there is need to use more advanced hybrid methods for better results in these complex problems

Table 3. ED with Cubic Cost Functions.

\begin{tabular}{lllll}
\hline Reference & Objectives & $\begin{array}{l}\text { Nature of objective } \\
\text { functions }\end{array}$ & $\begin{array}{l}\text { Number of } \\
\text { Constraints(n) }\end{array}$ & Method \\
\hline Z.X Liang et al,1991[29] & $\mathrm{T}$ & Static & - & Gram-Schmidt, Least Squares \\
Z.X Liang et al,1992 [30] & $\mathrm{T}$ & Static & 3 & Dynamic programming(DP) \\
A.Jiang and S.Ertem,1995 [31] & $\mathrm{T}$ & Static & 2 & Newton Method(NM) \\
B.S et al ,2013[32] & $\mathrm{T}, \mathrm{E}$ & $\begin{array}{l}\text { DED with ramp rates } \\
\text { and valve points }\end{array}$ & 4 & $\begin{array}{l}\text { Fuzzy Logic (FL), BF and Nelder-Mead(NM) } \\
\text { (FL-BF-NM) }\end{array}$ \\
Hari Mohan D.et al,2014[33] & $\mathrm{T}, \mathrm{E}$ & Static & 5 & PSO-General Search Algorithm (PSO-GSA) \\
Yusuf Somez,2013[37] & $\mathrm{T}$ & General static & 2 & ABC \\
Deepak Mishra et al,2006 [34] & $\mathrm{T}$ & General static & 2 & OR-Hopefield Neural Network \\
N.A Amoli et al,2012 [35] & $\mathrm{T}$ & Static & 2 & Firefly Algorithm \\
Krishnamurthy .S et al ,2012[36] & $\mathrm{T}, \mathrm{E}$ & Static & 2 & Langrange Method \\
T.Adhinarayananand M.Sydulu,2006[38] & $\mathrm{T}$ & Static & 2 & Lambda-logic based \\
T.Adhinarayananand M.Sydulu,2010 [39] & $\mathrm{T}$ & Static & 2 & Lambda-logic based \\
E.B Elanchezhian et al,2014[40] & $\mathrm{T}$ & Static & 8 & Teaching learning based optimization (TLBO) \\
\hline
\end{tabular}

Key

Q-Quadratic Function,

C-Cubic Function,

n- Number of objective

T-Thermal cost objective function

W-Wind, cost objective function

S-Solar cost objective function

E-Emissions cost objective function

TL-Transmission Losses)

Con-Number of constraints 


\section{MODED Formulation}

DED considers change-related costs. The DED takes the ramp rate limits, valve points and prohibited operating zone of the generating units into consideration. The general form of DED was formulated by Yusuf Somez, 2013[136] as is given by

$\mathrm{F}\left(P_{i j}\right)=\left\{a_{0, i}+\sum_{j=1}^{L=n} a_{j i} P_{t, i}^{j}+r_{i}\right\}+\left|e_{i} \sin f_{i}\left(P_{i}^{\min }-P_{i}\right)\right|(1)$

Where $a_{0, i}, a_{j, i}, e_{i}$ and $f_{i}$ are the cost coefficients of the $i^{\text {th }}$ unit, $P_{i}^{\min }$ is the lower generation bound for it unit and $r_{i}$ is the error associated with the ith equation. When $\mathrm{L}=3$, the cubic form of the SODED results. This can be expressed as

$$
\begin{gathered}
\mathrm{F}\left(P_{i, 3}\right)=f_{1}\left(x_{1}\right)=\min F=a_{3, i} P_{t, i}^{3}+a_{2, i} P_{t, i}^{2}+a_{1, i} P_{t, i}+ \\
a_{o, i}+r_{i}+\left|e_{i} \sin f_{i}\left(P_{i}^{\min }-P_{i}\right)\right|
\end{gathered}
$$

Also the SODED can be written as

$$
\min F=\sum_{t=1}^{M} \sum_{i=1}^{N} F_{t, i}\left(P_{i, m}\right)
$$

where $P_{i, m}$ is the output power of the $i^{\text {th }}$ unit at time $\mathrm{m}, \mathrm{N}$ is the number of generation units and $\mathrm{M}$ is the number of hours in the time horizon

To maximize the outcome of the Renewable energy(RE) systems, the implementation of ED combined Thermal and RE(TRE) systems has become of paramount importance. The formulations adopted in this paper are based on the work of Azza A. El Desouky,2013 [26]for the solar and John Hetzer et al ,2008 [41] for the wind cost functions. The operational cost objective function for wind power generation is formulated as

$$
\begin{gathered}
F\left(w_{i j}\right)=f_{2}\left(x_{2}\right)=F_{w i}\left(w_{i j}\right)+F_{p, w i}\left(w_{i j, a v}-w_{i j}\right)+ \\
F_{r, w i}\left(w_{i j}-w_{i j, a v}\right)
\end{gathered}
$$

In this case, $w_{i j}$ is the scheduled output of the $i^{\text {th }}$ wind generator in the $j^{\text {th }}$ hour

$F_{w i}\left(w_{i j}\right)$ is the weighted cost function representing the cost based on wind speed profile [26], $F_{p, w i}\left(w_{i j, a v}-w_{i j}\right)$ is the penalty cost for not using all the available wind power and $F_{r, w i}\left(w_{i j}-w_{i j, a v}\right)$ is the penalty reserve requirement cost which is due to the fact that that actual or available power is less than the scheduled wind power.

Similarly, the operational cost objective function for the $\mathrm{PV}$ power generation plant is formulated as [133]

$$
\begin{gathered}
F\left(P V_{i j}\right)=f_{3}\left(x_{3}\right)=F\left(P V_{i j}\right)+F_{p, P V i}\left(P V_{i j, a v}-P V_{i j}\right)+ \\
F_{r, P V i}\left(P V_{i j}-P V_{i j, a v}\right)\left(P V_{i j}\right)
\end{gathered}
$$

is the weighted cost function representing cost based on solar irradiance profile $F_{p, P V i}\left(P V_{i j, a v}-P V_{i j}\right)$ is the penalty cost for not using all the available solar power, and $F_{r, P V i}\left(P V_{i j}-\right.$ $\left.P V_{i j, a v}\right)$ is the penalty reserve requirement cost due to the fact that the actual or available power is less than the scheduled PV power.
While attempting to find an optimum DED of generation, transmission loss is one important constraint since the generating centers and the connected load exist in geographically distributed scenario. Since the power stations are usually spread out geographically, transmission network losses must be taken into account to achieve true economic dispatch. Network loss is a function of power injection at each node [30]. Where the real power system transmission losses, $\mathrm{PL}$, is expressed using B- coefficients by the relation

$$
P_{L}=\sum_{i=1}^{n} \sum_{j=1}^{n} P_{i} B_{i j} P_{j}+\sum_{i=1}^{n} P_{i} B_{0 i}+B_{00}
$$

Where $i$ is the number of generators , $j$ is the number of buses in the system, $B_{i j}$ is the $i j^{\text {th }}$ element of the loss coefficient Square matrix, $B_{o i}$ is the $i^{\text {th }}$ element of the loss coefficient matrix and $B_{00}$ is the constant loss coefficient .

When the loss expression is expanded for a particular number of generators and buses, the equation becomes

$$
\begin{gathered}
P_{L}=P_{n}^{3} \sum_{i=1}^{3}\left(B_{11} \frac{B_{1 n}}{B_{11}} \frac{P_{1 n}}{P_{1}}\right)+P_{n}^{2} \sum_{i=1}^{2}\left(B_{11} \frac{B_{1 n}}{B_{11}} \frac{P_{1 n}}{P_{1}}\right)+ \\
B_{0 n} P_{n}+\frac{B_{00}}{n}
\end{gathered}
$$

This can be expressed as a cubic function

$$
P_{L}=\alpha_{3} P_{n}^{3}+\alpha_{2} P_{n}^{2}+\alpha_{1} P_{n}+\alpha_{0}
$$

The cost of transmission line losses between plants are accounted with the actual fuel cost function by using a price factor $g$.This factor is defined as the ratio between the fuel cost at its maximum power output to the maximum power output .That is for this multi objective case

$$
g_{i}=\frac{\sum_{i=1}^{N} F\left(P_{i j, \max }\right)+\sum_{i=1}^{M} F\left(w_{i j, \max }\right)+\sum_{i=1}^{S} F\left(P V_{i j, \max }\right)}{P_{i, \max }}
$$

Thus, the cost function for the losses at a particular time becomes

$$
\mathrm{F}\left(P_{L, i}\right)=f_{4}\left(x_{4}\right)=\min F=\sum_{i=1}^{n} g_{i}\left(\alpha_{3, i} P_{t, i}^{3}+\alpha_{2, i} P_{t, i}^{2}+\right.
$$

Several works on combined economic and emissions dispatch (CEED) have been considered in the past research. Some of these can be found in [11],[19],[35],[42],[43],[44],[23],[45],[46],[47] [48] and [26];just to list a few. All these works have considered emissions using the quadratic function which is less accurate[29]. Consequently, the more accurate equation for estimating the emissions cost is the third (cubic) form and it is the function which will be used in the proposed research. It is given by

$$
\begin{gathered}
\mathrm{E}\left(P_{i j}\right)=\left\{\beta_{0, i}+\sum_{j=1}^{L=3} \beta_{j i} P_{t, i}^{j}+\left|\zeta_{j, i} \exp \left(\lambda_{j, i} P_{i}\right)\right|\right\} \\
\mathrm{E}\left(P_{i, 3}\right)=f_{5}\left(x_{5}\right)=\beta_{3, i} P_{t, i}^{3}+\beta_{2, i} P_{t, i}^{2}+\beta_{1, i} P_{t, i}^{1}+\beta_{0, i}+ \\
\zeta_{3, i} \exp \left(\lambda_{3, i} P_{i}\right)++\zeta_{2, i}
\end{gathered}
$$

From equations (2), (4), (5), (10) and (12), the MODED 
can be formulated as

$$
\begin{array}{r}
\min \mathrm{F}=\min \left[W _ { 1 } \left\{\sum_{i=1}^{N} F\left(P_{i j}\right)+\sum_{i=1}^{M} F\left(w_{i j}\right)+\right.\right. \\
\left.\left.\sum_{i=1}^{S} F\left(P V_{i j}\right)+\mathrm{F}\left(P_{L, i}\right)\right\}+W_{2} \mathrm{E}\left(P_{i, j}\right)\right]
\end{array}
$$

Or

$$
\min F=\min \left[W_{1} F+W_{2} E\right]=W F+(1-W)
$$

Where

$$
\begin{gathered}
F=\sum_{i=1}^{N} F\left(P_{i j}\right)+\sum_{i=1}^{M} F\left(w_{i j}\right)+\sum_{i=1}^{S} F\left(P V_{i j}\right)+ \\
\mathrm{F}\left(P_{L, i}\right) \text { and } E=\sum_{i=1}^{N, M, S} E\left(P_{i j}, P V_{i j}, w_{i j}\right)
\end{gathered}
$$

Subject to

$$
\begin{gathered}
\sum_{i=1}^{N} P_{i j}+\sum_{i=1}^{M} P w_{i j}+\sum_{i=1}^{S} P V_{i j}=P_{D j}+P_{\text {loss } j} \\
P_{i}^{\text {min }} \leq P_{i} \leq P_{i}^{\text {max }} \\
0 \leq w_{i} \leq w_{r i} \\
0 \leq P V_{i} \leq P V_{K_{\text {tmax }}} \\
P_{i j}-P_{i j-1} \leq U R_{i} \\
P_{i j-1}-P_{i j} \leq D R_{i} \\
\leq P_{l j} \leq P_{l}^{\text {max }} l=1,2,3 \ldots L \\
P_{i} \leq P^{P Z, L O W} \\
P_{i} \geq P^{P Z, H I G H} \\
P_{r}^{\text {max }}\left[\sum_{i}^{N} P_{i m}+\Omega\left(w_{i}+P V_{i}\right)\right] \leq P_{D j}+P_{\text {loss } j} \leq P_{a}
\end{gathered}
$$

$W_{1}$, and $W_{2}$ are non-negative weights used to make tradeoff (relative importance )between emission security and total fuel cost considering the three fuels such that $W_{1}+W_{2}$ $=1 . \mathrm{N}, \mathrm{M}$ and $\mathrm{S}$ are the number of thermal wind farm and PV power plants. $W_{1}$ Is the algebraic sum of the individual weight of the four objectives?

\section{Applications of 5-Objective MODED}

The MODED formulated can be used to investigate Multi Area Multi Objective Dynamic Economic Dispatch (MAMODED, Dynamic Reactive Power MODED (DRPMODED) and the Security Constrained MODED (SCMODED). These are discussed in this section.

The multi area single objective economic dispatch (MASOED) problem formulation is given by

$$
\min F=\min \sum_{m=1}^{M} \sum_{n=1}^{N_{M}}\left(a_{m n} P_{m n}^{2}+b_{m n} P_{m n}+C_{m n}\right)
$$

Where $P_{m n}$ Is the power output of generator $\mathrm{n}$ in area $\mathrm{m}, a_{m n}, b_{m n}$ and $c_{m n}$, are the fuel cost coefficients, $\mathrm{M}$ is the number

are $N_{M}$ is the number of online units for the area $\mathrm{M}$.

According to Jizhong Zhu, pp. 211-248, (2006) [1], many approaches have been considered for static MAED. These include NFP with multi area wheeling (NFPMAW), ONN,
AHP, DP, Spatial DP(SDP), EP and NLCNFP. Other methods of solving the MAED problems are explained in [49]-[59]. In these methods however, only static MAED is considered. When a MAED problem is solved with spinning reserve constraints and RE cost functions the problem becomes further complicated. The power allocation to each unit is done in such a manner that after supplying the total load, some specified reserve is left for security reasons. This is the dynamic MAED(MAMODED) problem In the event that the power in these areas is changing significantly, the classical methods of MAED solution are no longer applicable in such stochastic environments .Thus more advanced hybrids must be applied to solved the MADED problem which has gained a lot of interest with the integration of renewable energy into the grid .

Thus, the multi area single objective DED (MASODED) with a cubic objective function that is of interest in the proposed research is defined by the relation

$$
\begin{array}{r}
\min F_{S, M}=\min \sum_{m=1}^{M} \sum_{n=1}^{N_{M}}\left(a_{m n} P_{m n}^{3}+a_{m n} P_{m n}^{2}+\right. \\
\left.a_{m n} P_{m n}+a_{m n}+r_{m n}+\left|e_{m n} \sin f_{m n}\left(P_{m n}^{\min }-P_{m n}\right)\right|\right)
\end{array}
$$

The Multi Area Multi Objective DED (MAMODED) which incorporates the Renewable Energy, Transmission line and Emissions Cost functions can be represented by

$$
\min F_{M, M}=\min \sum_{m=1}^{M} \sum_{n=1}^{N_{k}} F_{M, N}\left(P_{m n}\right)
$$

Subject to Area power balance constraints (APBC)

$$
A P B C=\sum_{m=1}^{M} \sum_{n=1}^{N_{M}} P_{m n}-\sum_{m=1}^{M} \sum_{n=1}^{N_{d}} P_{D m n}-P_{l}=0
$$

Generator capacity limit constraint

$$
P_{m n, \min } \leq P_{m n} \leq P_{m n, \max }
$$

Tie-line power flow limit

$$
\left|P_{t}\right| \leq P_{t, \max } t=1,2,3 \ldots \ldots . N_{t}
$$

Uncertainty constraint

$$
P_{r}\left[\sum_{i}^{N} P_{i m}+\Omega\left(w_{i}+P V_{i}\right)\right] \leq P_{D m n j}+P_{L j} \leq P_{a}
$$

Generation constraint (GRC)

$$
\left|P_{m n}\right| \leq P_{m n, G R C}
$$

In this formulation, $\left(F_{M, M}\right)$ is the MAMODED problem to be solved in the proposed research, $m=1,2,3, \ldots . M$ (areas) $, \quad n=1,2,3, \ldots . N$ (units) and $k=1,2,3, \ldots . K_{n}$ (fuels, $P_{m n}$ is the power output of generator $\mathrm{n}$ in area $\mathrm{m} a_{m n}, b_{m n}, c_{m n}, d_{m n}$, and $e_{m n}$, are the fuel cost coefficients for area $m$ and unit n, $\quad N_{M}$ is the number of online units for the area $\mathrm{m}$, $P_{D \text { min }}$ is the active load at node $\mathrm{n}$ in the area $\mathrm{m}, P_{l}$ is the total real power loss for multi area system, $N_{d}$ is the number of loads in area m, $N_{t}$ is the number of tie lines and $P_{t}$ is the active power flow in the tie line $t$

The objectives of reactive power (VAR) optimization, which include RPED, are to improve the voltage profile, to 
minimize system active power losses, and to determine optimal VAR compensation placement under various operating conditions. To achieve these objectives, power system operators utilize control options such as adjusting generator excitation, transformer tap changing, shunt capacitors, and SVC. However, the size of power systems and prevailing constraints produce strenuous circumstances for system operators to correct voltage problems at any given time. In such cases, there is certainly a need for decision making tools in predominantly fluctuating and uncertain computational environments. There has been a growing interest in VAR optimization problems over the last decade. Methods applied so far to solve the SORPED are as found in [60]-[65].Solving ORPED is gaining more importance due to their effectiveness in handling the inequality constraints and discrete values compared to that of conventional gradientbased methods. EAs generally perform unconstrained searches, and they require some additional mechanism to handle constraints. In the literature, various constraint handling techniques have been proposed. However, to solve ORPD the penalty function approach has been commonly used, while the other constraint handling methods remain untested. However, the excessive time consumption of EP and GAs will limit their applications in power systems, especially during real - time operation. Thus better method are needed to handle the more complex problems where stochastic reactive power from wind and solar generators are involved.

The fuel cost in terms of reactive power output can be expressed as

$$
\mathrm{F}\left(Q_{g i}\right)=a_{q, o}+\sum_{j=1}^{L=n} a_{q i} Q_{g, i}^{j}
$$

where $a_{q, o}$ and $a_{q i}$ are the reactive power cost coefficients calculated using a curve fitting method $Q_{g i}$ is the reactive power generated by generator $i$ and $n$ is the order of the fuel cost function

Subject to

Power balance constraints

$$
\begin{aligned}
& P_{i}-V_{i} \sum_{j=1}^{N_{B}} V_{j}\left(G_{i j} \cos \theta_{i j}+B_{i j} \sin \theta_{i j}\right)=0, i= \\
& 1,2,3 \ldots \ldots N_{B}-1 \\
& Q_{i}-V_{i} \sum_{j=1}^{N_{P Q}} V_{j}\left(G_{i j} \sin \theta_{i j}-B_{i j} \cos \theta_{i j}\right)=0, i= \\
& 1,2,3 \ldots \ldots N_{P Q}
\end{aligned}
$$

Continuous control variable (Generator Bus Voltage)

$$
V_{i}^{\min } \leq V_{i} \leq V_{i}^{\max } i \in N_{B}
$$

Discrete control variable (Transformer Tap Settings)

$$
t_{k}^{\text {min }} \leq t_{k} \leq t_{k}^{\max } i \in N_{T}
$$

where $t_{k}$ is the tap setting of transformer at branch $\mathrm{k}$

State variables

$$
Q_{C i}^{\min } \leq Q_{C i} \leq Q_{C i}^{\max } i \in N_{C}
$$

$$
\begin{gathered}
Q_{g i}^{\min } \leq Q_{g i} \leq Q_{g i}^{\max } i \in N_{g} \\
\left|S_{i}\right| \leq S_{i}^{\max }, i \in N_{i}
\end{gathered}
$$

Reactive power balance

$$
\sum_{i=1}^{N_{G}} Q_{G i}+\sum_{j=1}^{N_{G}} Q_{c j}=\sum_{k=1}^{N_{D}} Q_{d k}+Q_{L}
$$

In this formulation $Q_{C i}$ is the reactive power generated by the ith capacitor bank, $Q_{g i}$ is the reactive power generated at bus i, $S_{i}$ is the apparent power flow through the ith branch, $N_{B}$ is the total number of buses, $N_{T}$ is the number of tap setting transformer branches, $N_{C}$ is the number of capacitor banks and $N_{g}$ is the number of generator buses, $Q_{G i}$ Reactive power generated by generator i, $Q_{c j}$ Reactive power generated and absorbed by VAR compensation device $\mathrm{j}$ such as capacitors,SVC,Wind Based DFIGs, and PV generators, $Q_{d k}$ Reactive power load at load bus $\mathrm{k}$ and $Q_{L}$ Power system reactive power power loss and absorption .Further, Where $V_{i}$ is the voltage magnitude at bus $\mathrm{i}, V_{j}$ is the voltage magnitude at bus $\mathrm{j}, P_{i}, Q_{i}$ is the real and reactive powers injected at bus $\mathrm{i}, G_{i j}, B_{i j}$ is the mutual conductance and suspectance between bus I and $\mathrm{j}, N_{B}-1$ is the total number of buses excluding the slack bus, $N_{P Q}$ is the number of PQ buses and $\theta_{i j}$ is the voltage angle difference between bus I and bus $\mathrm{j}$

The security - constrained economic dispatch (SCED) is one of the simplified optimal power flow (OPF) problems. It is widely used in power industry. The main objective of electric power dispatch is to provide electricity to the customers at low cost and high reliability. Transmission line failures constitute a great threat to the electric power system security.

The static single objective SCED (SSOSCED) problem is formulated as

$$
F_{S, S}=\sum_{i \in N_{G}} F_{i\left(P_{G i}\right)}
$$

Where $F_{i\left(P_{G i}\right)}=a_{2, i} P_{t, i}^{2}+a_{1, i} P_{t, i}+a_{o, i}$

The several approaches to solve the SCED from 1952 to 2014are presented in [1], [66], [67]-[71]. Single objective SCDED (SOSCDED) problem is formulated as

$$
F_{S, S}=\sum_{i \in N_{G}} F_{i\left(P_{G i}\right)}
$$

where $\quad F_{i\left(P_{G i}\right)}=a_{3, i} P_{t, i}^{3}+a_{2, i} P_{t, i}^{2}+a_{1, i} P_{t, i}+a_{o, i}+r_{i}+$ $\left|e_{i} \sin f_{i}\left(P_{i}^{\min }-P_{i}\right)\right|$

The SOSCDED in the proposed research uses the more accurate cubic function and incorporates the error, valve points and ram rate terms. The multi objective SCED(MOSCDED) which investigates the effects of renewable energy, power loss and emissions functions to the energy security of the power system is formulated as

$$
F_{S, M}=\sum_{i \in N_{G}} F_{i\left(P_{G i}\right)}
$$

Where 


$$
\begin{gathered}
F_{S, M}=\left[W _ { 1 } \left\{\sum_{i=1}^{N} F\left(P_{i j}\right)+\sum_{i=1}^{M} F\left(w_{i j}\right)+\sum_{i=1}^{S} F\left(P V_{i j}\right)+\right.\right. \\
\left.\left.\mathrm{F}\left(P_{L, i}\right)\right\}+W_{2} \mathrm{E}\left(P_{i, j}\right)\right]
\end{gathered}
$$

Subject to

$$
\begin{gathered}
\sum_{i \in N_{G}} P_{G i}=\sum_{k \in N_{D k}} P_{D k}+P_{l} \\
\left|P_{i j}\right| \leq P_{i j \max } i \in N_{T} \\
P_{G i \text { min }} \leq P_{G i} \leq P_{G i \text { max }} \\
P_{r}\left[\sum_{i}^{N} P_{i m}+\Omega\left(w_{i}+P V_{i}\right)\right] \leq P_{D j}+P_{\text {loss } j} \leq P_{a}
\end{gathered}
$$

\section{MODED Optimization Methods}

The methods that have been to solve the DED Problem so far can be classified into three groups. These are, Deterministic, Heuristic and Hybrid methods. These methods have been discussed in the following sub sections.

\subsection{Deterministic (D)}

Unconstrained Methods (UCM) convert constrained problems into unconstrained form. This forms the basics of the formulation of the constrained optimization Algorithms. These methods include Gradient Search (GS),Line Search(LS),Lagrange Multiplier(LM),Newton Raphson(NR) ,Trust Region (TR) ,Quasi-Newton (QN),Double-dogleg(DD) and Conjugate Gradient(CG) Methods. In DED Only LM method has been used by W.G. Wood, 1982 [72] and W.R. Barcelo and P. Rastgoufard,1997 [73] and Maclaurin Series-Based Lagrangian Method (MSBLM) was later applied to the DED problem by Hemamalini et al, 2010 [74].

Linear Programming (LP) linearizes the nonlinear power system DED problem so that the objective function and the constraints have the linear form. It was Ahmed Farag et al, 1995 [75] and Y.H. Song and I. Yu, 1997 [76] and it proved reliable in terms of convergence. The method was found Quick in identifying infeasibility and thus able to accommodate large variety of power system operating limits and contingency constraints. However the method was found inaccurate in evaluating the power system losses and therefore had insufficient ability to find an exact solution as compared with more accurate Non Linear models. However the DED solutions generally met the requirements of Engineering precision when applied to the SCED and RPED optimization [1].

Non Linear Programming (NLP) is a first order method .Since DED problems are nonlinear, the method able to handle the nonlinear objectives and constraints .A search direction is chosen and the search is done using reduced gradient method. As applied by P.P.J. van den Bosch, 1985 [77] and an improved version of NLP called Non Linear Constrained Method (NLCM) developed by Faisal .A. Mohamed, 2009 [11],the method has several advantages as compared to the LP Method .These include higher accuracy and global convergence, that is, convergence is guaranteed independent of the starting point. However the method has a slow rate of convergence due to a zigzagging problem in the search direction. The method has also been used in SCED, MAED and RPED problems [1].

Other deterministic methods that have been used to handle DED problems include Economic Load Allocation and Supplementary Control Action (ELASCA), Bechert and Kwatny, 1972 [8] ,Muller Algorithm (MA), Chandram et al, 2006 [78],Brent Method (BM), K. Chandram et al, 2008 [79] and Model Predictive Control (MPC), X. Xia et al, 1999 [80], $\mathrm{X}$. Xia et al,2011 [81] just to mention a few.

\subsection{Non Quantity Approaches (N)}

These methods are applied to problems with uncertainties in their parameter variations. Uncertainty due to insufficient information generate an uncertain region of decisions and therefore results from average values cannot be used to represent the uncertainty level. NQA methods are meant to account for the uncertainties in information and goals related to multiple and usually conflicting objectives in power system optimization .These methods find application in ED,HTS,UC,RPED and State Estimation problems with uncertainties. Compared to the deterministic methods, the NQA Methods are effective in handling uncertainties, that is, they compute the unavailable or uncertain data so that the MODED problem can be solved even when some data for the wind and solar objective cost functions are not available[1]. These methods include Optimization Neural Networks (ONN), Artificial Neural Network(ANN), Probabilistic /Characterization Theory (PT),Fuzzy Set Theory (FST),Analytical Hierarchical Process (AHP),Risk Management Tools(RMT) and Cost Benefit Analysis(CBA).These Methods have been used in the formulation of hybrids used in the solution of DED problems with uncertainties. Examples of such include,ANN [82],Heuristic Neural Network(HNN)[83-84],Trust Region (TR) and Goal Programming (GP) [85], Chaotic Fuzzy(CF) and Variable Step Size (VSS) [86].

\subsection{Heuristic (H)}

Evolutionary Algorithms (EAs) are based on natural evolution .They are population based optimization processes. There is no need to differentiate the cost functions and the constraints in the ED formulation. The method can be categorized as GA, EP and DE. The three however use the same mutation, recombination, reproduction, cross over and selection operators [1]. DED using Genetic Algorithms (GA) and the derived methods include Elitist Genetic Algorithm (EGA),Fly et al, 1997 [87], Parallel Micro GA (PMGA), Ongsakul et al 2002 [89] and Elitist non-dominated sorting genetic algorithm-II (ENSGA-II), Robert.T.F et al,2004[90].Evolutionary Programming (EP) include Constrained Evolution Programming (CEP), Shailti et al, 2005 [91]. EP, Joned et al, 2006 [92] and Quantum Evolutionary Algorithm (QEA), Babu et al, 2008 [93]. Differential Evolution (DE) is the most recent EA and the DED works done include Modified DE (MDE), Yuang et 
al ,2008 [4], K.Deb,2000 [94],Variable Scaling Hybrid Differential Evolution (VSHDE), J.Chiou,2009 [95] and Cellular Differential Evolution (CDE) Noman and Iba, 2011 [96].EAs methods have been used to solve simplified CED, DED SCED RPED and MAED problems. However these methods require all information to be included in the fitness function therefore it is difficult to consider all the MODED problem objectives and constraints in the objective function.

Particle Swarm Optimization (PSO) includes all the swarm intelligence algorithms inspired by the social dynamics and an emergent behavior that arises in socially organized colonies. These methods have been used in all hybrid algorithms where an accurate search is needed in DED problems. They include Particle Swarm Optimization (PSO) Z.L. Gaing, 2004 [97], Hardiansyah et al 2012[98], Zhao et al, 2004 [42] and Modified Adaptive PSO (MAPSO), Niknam et al, 2011[99].More specific PSO methods used in DED problems are BAT Algorithm, Anti Colony Optimization(ACO),Bee Colony Optimization(BCO),Artificial Bee Colony (ABC),Bacterial Foraging (BF),BAT Algorithm, Teacher Learning Algorithm(TLA) , Bandi Ramesh et al, 2013[44],Biogeography-Based Optimization (BBO), Divya Mathur, 2013,[100].

Other Methods that have been used in DED include Simulated Annealing (SA), Panigrahi et al, 2006 [101],Pattern Search (PS),Alsumait et al, 2010 [22],Adaptive Look-Ahead (ALA), Han et al, 2001 [102],Feasibility-Based Selection Comparison (FBSC),K.Deb,2000 [94],Ongsakul et al, 2002 [103], X.Yuan et al,2009[104],Artificial Immune System (AIS), M.Basu, 2011[105] Hemmalini et al,2011 [106],Modified Teaching-Learning Algorithm (MTLA) Niknam, T et al ,2013 [107] and Optimality Condition Decomposition (OCD), Rabiee, A et al , 2014 [108]

\subsection{Hybrids}

The reason for increased use of hybrids is because they exalt the strengths and improve the weaknesses of the methods concerned. Deterministic,Heuristic and NonQuantity Approaches are used in hybrid formation .There are two types of hybrids depending on the number and Type of methods used.

\subsection{Two Method Hybrids}

There are eight possible types of two-method hybrids. These include N-N, N-D, and N-H, D-D, D-H, D-N, H-D, H$\mathrm{H}$ and $\mathrm{H}-\mathrm{H}$ approaches.

Deterministic-Deterministic (D-D): These method involve two deterministic methods .They include Quadratic Programming (QP) and Linear Programming (LP) - (QP-LP), Somuah and Khunaizi, 1990 [109], QP-LP, Han et al, 2001 [110] and Interior Point (IP) and Quadratic Programming (QP) - (IP-QP), Lin and Chen, 2002[111]

Deterministic-Heuristic (D-H): These involve a deterministic method with a Heuristic method to fine tune it. These include SA and GA - (SA-GA), Ongsakul et al, 2001
[112], SQP-EP, Deterministically Guided (DG) PSO (DGPSO), Victoire et al, 2005 [113-115] and SA and Direct Search Method (DSM)-(SA-DSM), C .Chen, 2007 [18]

Deterministic- Non Quantity Approaches (D-N) or Non Quantity Approaches-Deterministic (N-D): This involves a base deterministic method with a non-quantity method to deal with the uncertainities. The vice versa is also true. Examples in this context include Lambda-Iteration Technique (LIT) and Artificial Neural Networks (ANN)-(LIT-ANN), R.H Liang, 1999 [82] and Heuristic Neural Networks (HNN) and QP (HNN-QP), Abdul-Aziz et al, 2008 [83-84].

Heuristic -Deterministic (H-D): In this case a hybrid method is used as the base algorithm then its weaknesses are strengthened using a deterministic method. In DED ,examples include Genetic Algorithm (GA) and Gradient Search (GS)-(GA-GS), F.Li et al, 1997 [116], Relaxed GA (RGA) and Gradient Search (GS)-(RGAGS) ,Li and Aggarwal,2000 [117],EP and Sequential QP (EPSQP), P.A et al, 2002 [118],PSO-SQP, Victoire et al,2005 [113-115],Swarm Direction Technique (SDT) and Fast Evolutionary Programming (FEP) -(SDT-FEP), Zwe-Lee et al,2009 [119],Evolution (DE) and Local Random Search (LRS)-(DE-LRS), Y. Lu et al, 2009 [120],Improved Differential Evolutionary (IDE) and Shor's Algorithm (SHA)-(IDE-SHA), Yuan et al,2009 [104], F.Kappel and A.V Kuntsevich,2000 [121],PSO and Harmony Search (HS)(PSO-HS), Ravikumar et al,2011 [122] ,Seeker Optimization Algorithm (SOA) and SQP- (SOA-SQP), S. Sivasurbramani et al,2010 [123],Hybrid Differential Evolution (HDE) and Sequential Quadratic Programming (SQP)-(HDE-SQP), A. M. Elaiw,2012 [124] ,Real Coded GA (RCGA) with QuasiSimplex (QS)-(RCGA-QS), Zhang et al, 2006 [125]

Heuristic- Heuristic $(\mathrm{H}-\mathrm{H})$ : In this type two heuristic methods are involved, on serves as the base and the other is used to improve the weaknesses of the first for accurate results. Examples include PSO and DE (PSO-DE), Dun -Wei Gong et al, 2010[126],Firefly Algorithm (FA) with GA Mutation (GAM)-(FA-GAM) , Niknam, T,2012 [127],Multi Objective PSO (MOPSO) and Brent method(BM)-(MOPSOBM), H. Shayeghi and A. Ghasemi ,2012[128],Modified Artificial Bee Colony (MABC) with Differential Evolution (DE)-(MABC-DE), Hardiansyah ,2013[129] and PSO and Simulated Annealing (SA) -(PSO-SA),V.Karthikeyan et al,2013[ 130]

Non Quantity Approaches-Heuristic (N-H) 0r HeuristicNon Quantity Approaches (H-N): In this case a non -quantity method is used to address an uncertainty before a heuristic method is applied. The vice versa is also true Examples include Fuzzy Optimization Technique (FOT) and Goal Satisfaction Concept (GSC)-(FOT-GSC) P.A et al, 2004 [131] and Chaotic Differential Evolution (CDE), Y.Lu et al,2011 [132].

Non Quantity Approaches-Non Quantity Approaches (N$\mathrm{N})$ : Since non quantity methods are only used to address uncertainities, then a combination of two or more of such methods in the formulation of an hybrid is not feasible. 


\subsection{Three Method Hybrids}

Recent trends in Hybrid formation involve the use of three methods. There are twenty seven possible three-method hybrids that can be used. In this section we discuss such methods that have been used in DED solution. These are summarized in Table 4

Heuristic algorithms seem to have shared the same dominance as deterministic algorithms. This is because heuristic algorithms, unlike deterministic ones, are derivative-free, and capable of solving optimization problems without requiring convexity. They are also independent of the initial solution, and have the ability to avoid being trapped in local optima.

On the other hand, heuristic algorithms have drawbacks such as being problem dependent, requiring parameter tuning, and unable to guarantee global solution attainment. A combination of a both methods into a hybrid has proved to solve this problem. This explains why publishing research work using hybrid methods has been becoming increasingly popular. This is as shown in Figure 3.

Also in the last decade integration of RE cost function has been of increasing interest. This is because RE is well utilized once in the national grid. Therefore, better methods for handling DED with wind and solar cost functions need to be developed.

Table 4. Three Method Hybrids used in DED.

\begin{tabular}{ll}
\hline Type & Examples in DED \\
\hline H-H-D & EP, PSO, and SQP (EP-PSO-SQP), S. Titus and A.E Jeyakumar,2008 [133] \\
H-H-H & BF-PSO-DE, Praveena et al ,2010 [134] \\
H-D-H & GA and Local Search(LS) -Goal Programming(GP) -(GA-LS-GP), A.A.Mousa et al,2011 [135] \\
D-H-H & $\begin{array}{l}\text { Mixed Integer Quadratic Programming (MIQP), the Warm Start Technique (WST) and the Range Restriction Scheme (RRS)-(MIQP-WST- } \\
\text { RRS), Wang et al, 2014 [136] }\end{array}$ \\
N-N-H & $\begin{array}{l}\text { Variable Step Size(VSS) Chaotic Fuzzy(CF) Quantum Genetic Algorithm, (VSS-CF-QGA), Wenxia Liu, et al,2014[86] Trust Region (TR),Goal } \\
\text { Programming(GP) and PSO (TR-GP-PSO), Amhed et al,2013[48] }\end{array}$ \\
\hline
\end{tabular}



GHBRID DETERMINISTIC HEURISTIC

Figure 3. Journals on DED Published Using Various Methods[3].

\section{Conclusion}

This paper has psesented a detailed review of the MODED problem in terms of the formulation and the methods applied in the solution.It is apparent that cubic cost functions are found to be more accurate than quadratic ones. Further, fully constrained 5-Objective MODED with cubic functions to give more realistic results. However fourth order functions are predicted to be even better than the third order systems.

Dynamic trade in power is supposed be cheaper than the static one as the Improved Wheel Method (IWM) will be more realistic in modelling the areas and the tie lines. Dynamic reactive power (two-way) from the renewable sources will provide a far much improved voltage profile as compared to the static reactive power. In addition, there is foreseen better security due to the full constraining (with, uncertainty) and two way reactive power.

Therefore, there will be a more accurate MODED modelling ,new and better method for MODED Solution, Improved power system Security, dynamic MAED and a new way for Reactive Power Dispatch.

A more recent trend for solving MODED is the threemethod hybrids formulation in which all the weaknesses of the base methods are suppressed and the strengths exalted. This leads to increased accuracy and speed in handling higher order cost functions with more objectives.

\section{References}

[1] Jizhong Zhu (2009) Optimization of Power System Operation, New Jersey \&Canada: John Wiley and Sons. 
[2] N.P. Padhy,"Unit Commitment-a Bibliographical Survey," Power Systems, IEEE Transactions on, Vol. 19, No. 2, pp. 1196-1205, 2004.

[3] http://www.sciencedirect.com/science,April 2015.

[4] J.A. Momoh, M.E. El-Hawary and R. Adapa,"A Review of Selected Optimal Power Flow Literature to 1993. II. Newton, Linear Programming and Interior Point Methods," Power Systems, IEEE Transactions on, Vol. 14, No. 1, pp. 105-111, 1999.

[5] M.R. AlRashidi and M.E. El-Hawary, "Applications of Computational Intelligence Techniques for Solving the Revived Optimal Power Flow Problem, "Electrical. Power Syst. Res., Vol. 79, No. 4, pp. 694-702, 2009.

[6] A. Mahor, V. Prasad and S. Rangnekar,"Economic Dispatch using Particle Swarm Optimization: A Review," Renewable and Sustainable Energy Reviews, Vol. 13, No. 8, pp. 21342141, 2009

[7] H. Altun and T. Yalcinoz,"Implementing Soft Computing Techniques to Solve Economic Dispatch Problem in Power Systems," Expert Systems Applications, Vol. 35, No.4, pp. 1668-1678, 2008.

[8] T.E. Bechert and H.G. Kwatny, "On the Optimal Dynamic Dispatch of Real Power," Power Apparatus and Systems, IEEE Transactions on, Vol. PAS-91, no.3, pp. 889-898, 1972.

[9] T.E. Bechert and Nanming Chen,"Area Automatic Generation Control by Multi-Pass Dynamic Programming," Power Apparatus and Systems, IEEE Transactions on, Vol. 96, no. 5, pp. 1460-1469, 1977.

[10] X. Xia and A.M. Elaiw,"Optimal Dynamic Economic Dispatch of Generation: A Review," Electrical Power Systems Res., Vol. In Press, Corrected Proof, 2010.

[11] Faisal A. Mohamed et al "Environmental/Economic Power Dispatch of Micro Grid Using Multiobjective Optimization" International Conference on Renewable Energies and Power Quality (ICREPQ'09) Valencia (Spain), 15th to 17th April, 2009.

[12] M.A. Abido and J.M. Bakhashwain " A Novel Multiobjective Evolutionary Algorithm for Optimal Reactive Power Dispatch Problem" in Proceedings of the 2003 10th IEEE International Conference on Electronics, Circuits and Systems, 2003 (ICECS 2003), IEEE, Vol. 3, pp.1054--1057, December 2003.

[13] Zhao Bo and Cao Yi-Jia "Multiple objective particle swarm optimization technique for economic load dispatch" Journal of Zhejiang University of Science and Technology Vol.6 No.5 pp.420-427 2005 .

[14] M.A. Abido." Multiobjective Optimal VAR Dispatch Using Strength Pareto Evolutionary Algorithm" in 2006 IEEE Congress on Evolutionary Computation (CEC'2006), pp. 2745--2751, IEEE, Vancouver, BC, Canada, July 2006.

[15] M. Basu, "Particle Swarm Optimization Based GoalAttainment Method for Dynamic Economic Emission Dispatch," Electric Power Components and Systems, Vol. 34, No. 9, pp. 1015-1025, 2006.

[16] Amitah Mahor et al "Economic dispatch using particle swarm optimization: A review" Renewable and Sustainable Energy Reviews, Vol 11, pp. 2134-2141,2009.
[17] M. Basu, "Dynamic Economic Emission Dispatch using Evolutionary Programming and Fuzzy Satisfying Method," International Journal of Emerging Electric Power Systems, Vol. 8, No. 4, pp. 1-15, 2007.

[18] C.-. Chen, "Simulated Annealing-Based Optimal WindThermal Coordination Scheduling," Generation, Transmission \& Distribution, IET, Vol. 1, no. 3, pp. 447-455, 2007.

[19] M. Basu, "Dynamic Economic Emission Dispatch using Non dominated Sorting Genetic Algorithm-II," International Journal of Electrical Power \& Energy Systems, Vol. 30, No. 2, pp. 140-149, 2008.

[20] R.P. Brent, Algorithms for Minimization without Derivatives, N.J.: Prentice-Hall,Englewood Cliffs, 1973.

[21] Zwe-Lee Gaing and Ting-Chia Ou, "Dynamic Economic Dispatch Solution using Fast Evolutionary Programming with Swarm Direction," Industrial Electronics and Applications, 2009. ICIEA 2009. 4th IEEE Conference on, pp. 1538-1544, 2009.

[22] J.S. Alsumait, M. Qasem, J.K. Sykulski and A.K. Al-Othman, "An Improved Pattern Search Based Algorithm to Solve the Dynamic Economic Dispatch Problem with Valve-Point Effect," Energy Conversion and Management, Vol. 51, No. 10, pp. 2062-2067, 2010.

[23] S Subramanian and S Ganesan. "A Simple Approach for Emission Constrained Economic Dispatch Problems" International Journal of Computer Applications Vol. 8, No. 11 pp39-45, October 2010.

[24] Chunghun Kim; Yonghao Gui; Chung Choo Chung; YongCheol Kang, "Model predictive control in dynamic economic dispatch using Weibull distribution," Power and Energy Society General Meeting (PES), 2013 IEEE , Vol.10, pp.1,5, 21-25 July 2013.

[25] Haiwang Zhong; Qing Xia; Yang Wang; Chongqing Kang, "Dynamic Economic Dispatch Considering Transmission Losses Using Quadratically Constrained Quadratic Program Method," Power Systems, IEEE Transactions on , Vol.28, No.3, pp.2232-2241, Aug. 2013.

[26] Azza a. Eldesouky,"Security and stochastic economic dispatch of power system including wind and solar resources with environmental consideration" International journal of renewable energy research Vol.3, No.4 pp. 951-958, 2013.7.

[27] Bakirtzis, E.A; Ntomaris, AV.; Kardakos, E.G.; Simoglou, C.K.; Biskas, P.N.; Bakirtzis, AG., "A unified unit commitment Economic dispatch model for short-term power system scheduling under high wind energy penetration," European Energy Market (EEM), 2014 11th International Conference on the, Vol.4, pp.1,6, 28-30 May 2014.

[28] Soubache ID and Sudhakara Reddy "solution Combined Economic and Emission Dispatch" American Journal of Engineering Science and Research Vol 1, No 1, pp 1-5 2014.

[29] Z.X Liang and J.D Glover "Improved cost functions for Economic Dispatch compensations "Power Systems IEEE Transactions on Vol 6.pp 821-829,1991.

[30] Z.X Liang and J.D Glover "A zoom feature for a Dynamic Programming Solution to Economic Dispatch including transmission Loses" Power Systems IEEE Transactions on Vol 7.pp 544-550, 1992. 
[31] A.jiang and S.Ertem "Economic Dispatch with nonmonotonically increasing incremental cost units and transmission system losses" Power Systems IEEE Transactions on Vol 10. pp 891-897, 1995.

[32] Bharathkumar.S et al "Multi Objective Economic Load Dispatch using Hybrid Fuzzy, Bacterial Foraging -NelderMead Algorithm "International Journal of Electrical Engineering and Technology, Vol 4, Issue 3 pp. 43-52, May June 2013.

[33] Hari Mohan D.et al "A Fuzzy field improved hybrid PSOGSA for Environmental /Economic power dispatch "International Journal of Engineering Science and Technology, Vol.6, No.4,pp.11-23,2014.

[34] Deepak Mishra et al "OR-Neuron Based Hopfield Neural Network for Solving Economic Load Dispatch Problem "Letter and Reviews for Neural Information Processing,Vol.10,No.11 pp249-259,November 2006.

[35] N.A Amoli et al "Solving Economic Dispatch Problem with Cubic Fuel Cost Function by Firefly Algorithm" Proceedings of the $8^{\text {th }}$ International Conference on Technical and Physical Problems of Power Engineering,ostfold University College Fredrikstad,Norway.pp 1-5,5-7 $7^{\text {th }}$ September 2012.

[36] Krishnamurthy, S.; Tzoneva, R., "Impact of price penalty factors on the solution of the combined economic emission dispatch problem using cubic criterion functions," Power and Energy Society General Meeting, 2012 IEEE, vol., no., pp.1,9, 22-26 July 2012.

[37] Yusuf Sonmez "Estimation of Fuel cost curve parameters for thermal power plants using the ABC Algorithm" ,Turkish Journal Of Electrical Engineering and Computer Science, Vol .21 pp. 1827-1841,2013.

[38] T.Adhinarayanan and M.Sydulu " Fast and effective Algorithm for Economic Dispatch of Cubic Fuel Cost based thermal units "First international conference on industrial and information systems ,ICIIS ,2006, Sirlanka , $8^{\text {th }}-11^{\text {th }}$ August 2006.

[39] T.Adhinarayanan and M.Sydulu "An effective non-iterative $\lambda$-Logic Based algorithm for Economic Dispatch of generators with cubic fuel cost function" Electrical power and energy systems , vol 32,pp 539-542,2010.

[40] E.B Elanchezhian et al "Economic Dispatch with cubic cost models using Teaching learning Algorithm " IET Generation,Transmission and Distribution, vol 8 issue 7 ,pp 1187-1202,2014.

[41] John Hetzer et al "An Economic Dispatch Model Incorporating Wind Power"IEEE Transactions on Energy Conversion, Vol .23, No.2 June 2008.

[42] Bo Zhao, Chuangxin Guo and Yijia Cao, "Dynamic Economic Dispatch in Electricity Market using Particle Swarm Optimization Algorithm," Intelligent Control and Automation, 2004. WCICA 2004. Fifth World Congress on, Vol. 6, pp. 5050-5054, 2004.

[43] M. Basu, "Particle Swarm Optimization Based GoalAttainment Method for Dynamic Economic Emission Dispatch," Electric Power Components and Systems, Vol. 34, No. 9, pp. 1015-1025, 2006.

[44] Bandi ramesh et al "Application of BAT algorithm for Combined Economic Load and Emission Dispatch" IJEETC Vol 2 No1.pp 2512-2523, 2013.
[45] Zhao Bo and Cao Yi-Jia "Multiple objective particle swarm optimization technique for economic load dispatch" Journal of Zhejiang University of Science and Technology Vol.6 No.5 pp.420-427 2005.

[46] Amitah Mahor et al "Economic dispatch using particle swarm optimization: A review" Renewable and Sustainable Energy Reviews, Vol 11, pp. 2134-2141,2009.

[47] A. A. Mousa et al "A Hybrid Optimization Technique Coupling an Evolutionary and a Local Search Algorithm for Economic Emission Load Dispatch Problem "Journal of Applied Mathematics, Vol.2, pp. 90-898,2011.

[48] Ahmed Ahmed El-Sawy et al, "Reference Point Based TRPSO for Multi-Objective Environmental/Economic Dispatch “Journal Applied Mathematics, 2013, Vol 4,pp 803-813,2013.

[49] Streiffert, D., "Multi-area economic dispatch with tie line constraints," Power Systems, IEEE Transactions on, Vol.10, No.4, pp.1946, 1951, Nov. 1995.

[50] T. Jayabarathi, G. Sadasivam and V. Ramachandran , "Evolutionary Programming-Based Multiarea Economic Dispatch with Tie Line Constraints", Electric Machines \& Power Systems, pp 1165-1176,2000.

[51] P. s. manoharan et al , 2009, "A Novel EP Approach for Multiarea Economic Dispatch with Multiple Fuel Options "Turk $J$ Electrical Engineering \& Computer Science Vol.17, No.1, PP1-19, 2009.

[52] Prasanna.T.S and Somasundaram. P "Multi-Area Security Constrained Economic Dispatch by Fuzzy- Stochastic Algorithms" Journal of Theoretical and Applied Information Technology, pp 88-94, 2009.

[53] S.Chitra Selvi et al "Hybrid Evolutionary Programming Approach to Multi-Area Unit Commitment with Import and Export Constraints" International Journal of Recent Trends in Engineering, Vol.1,No. 3, 223-228, May 2009.

[54] Manisha Sharma et al, "Multi-area economic dispatch with tie-line constraints employing evolutionary approach" International Journal of Engineering, Science and Technology Vol. 2, No. 3, pp. 132-149, 2010.

[55] Manisha Sharma et al "Reserve Constrained Multi-Area Economic Dispatch Employing Evolutionary Approach "International Journal of Applied Evolutionary Computation Vol .1 Issue 3 pp. 49-69 July 2010.

[56] Sudhakar A.V.V et al "Multi Area Economic Dispatch using Secant Method" Journal of Electrical Engineering Technology Vol. 8, No. 4: 744-751,2013.

[57] Huynh This and Thanh Binh "Hybrid Particle Swarm Optimization for Solving Multi-Area Economic Dispatch Problem" International Journal on Soft Computing (IJSC) Vol.4, No.2, pp. 17-27 May 2013.

[58] M.Basu“Artificial bee colony optimization for multi-area economic dispatch "International Vol. 49, July 2013, pp. 181$187,2013$.

[59] De,Shankha Suvr et al "Artificial Immune System for MultiArea Economic Dispatch" International Journal of Emerging Electric Power Systems Vol. 14, Issue 6, pp.581-590, Dec 2013. 
[60] Lee, K.Y.; Park, Y.M.; Ortiz, J. L., "A United Approach to Optimal Real and Reactive Power Dispatch," Power Apparatus and Systems, IEEE Transactions on, Vol.PAS-104, No.5, pp.1147,1153, May 1985.

[61] Q.H. Wu, Y.J. Cao, J.Y. Wen"Optimal reactive power dispatch using an adaptive genetic algorithm" International Journal of Electrical power and energy systems Vol.20, Issue 8, Pages 563-569, November 1998

[62] Serrano, B. R.; Vargas, A., "Active-reactive power economic dispatch of very short term in competitive electric markets," Power Technology Proceedings, 2001 IEEE Porto, Vol.1, No.10 pp.6-8, 2001.

[63] Worawat Nakawiro et al "A Novel Optimization Algorithm for Optimal Reactive Power Dispatch: A Comparative Study" IEEE Transactions on Power Systems, Vol.1 pp. 1155-1161, 2011.

[64] R. Mallipeddi et al "Efficient constraint handling for optimal reactive power dispatch problems" Swarm and Evolutionary Computation Vol. 5, Pages 28-36, August 2012.

[65] Lopez, J.C.; Munoz, J.I.; Contreras, J.; Mantovani, J. R S, "Optimal reactive power dispatch using stochastic chanceconstrained programming," Transmission and Distribution: Latin America Conference and Exposition (T\&D-LA), 2012 Sixth IEEE/PES, Vol.3, pp.1-7, 3-5 Sept. 2012.

[66] A. M. Elaiw, X. Xia,and A. M. Shehata "Dynamic Economic Dispatch Using Hybrid DE-SQP for Generating Units with Valve-Point Effects" Hindawi Publishing Corporation Mathematical Problems in Engineering Vol. 20,pp 1-10,2012.

[67] Kyoung-Shin Kim; Leen-Hark Jung; Lee, K.Y.; Un-Chul Moon, "Security Constrained Economic Dispatch Using Interior Point Method," Power System Technology, 2006. PowerCon 2006. International Conference on, Vol.12, pp.1-6, 22-26 Oct. 2006.

[68] Prasanna. T.S, Somasundaram. P "Multi-Area Security Constrained Economic Dispatch by Fuzzy- Stochastic Algorithms "Journal of Theoretical and Applied Information Technology pp. 88-94, 2009.

[69] Lizhi Wang and Nan Kong "Security Constrained Economic Dispatch: A Markov Decision Process Approach with Embedded Stochastic Programming" Industrial and Manufacturing Systems Engineering Iowa State University 3016 Black Engineering, Ames, IA 50014, USA PP 1-14,2010.

[70] Cvijic, S.; Jinjun Xiong, "Security constrained unit commitment and economic dispatch through benders decomposition: A comparative study," Power and Energy Society General Meeting, 2011 IEEE, Vol.10, pp.1-8, 24-29 July 2011.

[71] K.Vaisakh, P. Praveena, S. Rama Mohana Rao, Kala Meah, "Solving dynamic economic dispatch problem with security constraints using bacterial foraging PSO-DE algorithm" International Journal of Electrical Power \& Energy Systems, Vol. 39, Issue 1, Pages 56-67, July 2012.

[72] W.G. Wood, "Spinning Reserve Constrained Static and Dynamic Economic Dispatch," Power Apparatus and Systems, IEEE Transactions on, Vol. PAS-101,no.2, pp. 381-388, 1982.

[73] W.R. Barcelo and P. Rastgoufard,"Dynamic Economic Dispatch using the Extended Security Constrained Economic Dispatch Algorithm," Power Systems, IEEE Transactions on, Vol. 12, no. 2, pp. 961-967, 1997.
[74] S. Hemamalini and S.P. Simon, "Dynamic Economic Dispatch using Maclaurin Series Based Lagrangian Method," Energy Conversion and Management, Vol. 51, no. 11, pp. 2212-2219, 2010.

[75] Ahmed Farag et al, "Economic load dispatch multiobjective optimization Procedures using linear programming techniques" IEEE Transactions on Power Systems, Vol. 10, No. 2, pp 731738 May 1995.

[76] Y.H. Song and I. Yu,"Dynamic Load Dispatch with Voltage Security and Environmental Constraints," Electrical Power Systems. Res., Vol. 43, no. 1, pp. 53-60, 1997.

[77] P.P.J. van den Bosch,"Optimal Dynamic Dispatch Owing to Spinning-Reserve and Power-Rate Limits," Power Apparatus and Systems, IEEE Transactions on, Vol. PAS-104, no. 12, pp. 3395-3401, 1985.

[78] K. Chandram, N. Subrahmanyam and M. Sydulu,"Dynamic Economic Dispatch by Equal Embedded Algorithm," Electrical and Computer Engineering, 2006.ICECE '06. International Conference on, pp. 21-24, 2006.

[79] K. Chandram, N. Subrahmanyam and M. Sydulu,"Brent Method for Dynamic Economic Dispatch with Transmission Losses," Transmission and Distribution Conference and Exposition, 2008. T\&D. IEEE/PES, pp. 1-5, 2008.

[80] Xiaohua Xia, Jiangfeng Zhang and A. Elaiw, "A Model Predictive Control Approach to Dynamic Economic Dispatch Problem," Power Tech, 2009 IEEE Bucharest, pp. 1-7, 2009.

[81] X. Xia, J. Zhang and A. Elaiw, "An Application of Model Predictive Control to the Dynamic Economic Dispatch of Power Generation," Control Eng. Pract. Vol.19, no. 6, pp. 638-648, 2011.

[82] Ruey-Hsum Liang, "A Neural-Based Dispatch Approach to Dynamic Generation Allocation," Power Systems, IEEE Transactions on, Vol. 14, No. 4, pp.1388-1393, 1999

[83] A.Y. Abdelaziz, M.Z. Kamh, S.F. Mekhamer and M.A.L. Badr, "A Hybrid HNNQP Approach for Dynamic Economic Dispatch Problem," Electrical Power Systems. Res. Vol. 78, No. 10, pp. 1784-1788, 2008.

[84] A.Y. Abdelaziz, S.F. Mekhamer, M.Z. Kamh and M.A.L. Badr, "A Hybrid Hopfield Neural Network-Quadratic Programming Approach for Dynamic Economic Dispatch Problem," Power System Conference, 2008. MEPCON 2008.12th International Middle-East, pp. 565-570, 2008.

[85] Ahmed Ahmed El-Sawy et al, "Reference Point Based TRPSO for Multi-Objective Environmental/Economic Dispatch “Journal Applied Mathematics, 2013, Vol 4,pp 803-813,2013.

[86] Wenxia Liu, Yuying Zhang, Bo Zeng Shuya Niu, Jianhua Zhang, and Yong Xiao "An Environmental-Economic Dispatch Method for Smart Microgrids Using VSS_QGA" Hindawi Publishing Corporation Journal of Applied Mathematics Vol.24, pp. 1-11 2014.

[87] F. Li, R. Morgan and D. Williams, "Towards More Cost Saving Under Stricter Ramping Rate Constraints of Dynamic Economic Dispatch Problems-a Genetic Based Approach," Genetic Algorithms in Engineering Systems: Innovations and Applications, 1997. GALESIA 97. Second International Conference on (Conf.Publ. no. 446), pp. 221-225, 1997. 
[88] W. Ongsakul and J. Tippayachai, "Parallel Micro Genetic Algorithm Based on Merit Order Loading Solutions for Constrained Dynamic Economic Dispatch," Electrical Power Systems. Res., Vol. 61, no. 2, pp. 77-88, 2002.

[89] W. Ongsakul and J. Tippayachai, "Parallel Micro Genetic Algorithm Based on Merit Order Loading Solutions for Constrained Dynamic Economic Dispatch," Electrical Power Systems. Res., Vol. 61, no. 2, pp. 77-88, 2002.

[90] Robert T. F. Ah King et al "Evolutionary Multi-Objective Environmental/Economic Dispatch: Stochastic vs. Deterministic Approach" Department of Electrical and Electronic Engineering, Faculty of Engineering, University of Mauritius, Reduit, Mauritius, pp. 1-15,2004.

[91] K. Shailti Swamp and A. Natarajan, "Constrained Optimization using Evolutionary Programming for Dynamic Economic Dispatch, "Intelligent Sensing and Information Processing, 2005. Proceedings of 2005 International Conference on, pp. 314-319, 2005.

[92] A.M.A.A. Joned, I. Musirin and Titik Khawa Abdul Rahman, "Solving Dynamic Economic Dispatch using Evolutionary Programming," Power and Energy Conference, 2006. PECon '06. IEEE International, pp. 144-149, 2006.

[93] G.S.S. Babu, D.B. Das and C. Patvardhan, "Dynamic Economic Dispatch Solution using an Enhanced RealQuantum Evolutionary Algorithm," Power System Technology and IEEE Power India Conference, 2008. POWERCON 2008. Joint International Conference on, pp. 1-6, 2008.

[94] K. Deb, "An Efficient Constraint Handling Method for Genetic Algorithms, "Computer Methods Applications in Mechanical Engineering, Vol. 186, no. 2-4, pp. 311-338, 2000.

[95] J. Chiou, "A Variable Scaling Hybrid Differential Evolution for Solving Large-Scale Power Dispatch Problems," Generation, Transmission \& Distribution, IET, Vol. 3, No. 2, pp. 154-163, 2009.

[96] Noman, N.; Iba, H.,"Solving dynamic economic dispatch problems using cellular differential evolution," Evolutionary Computation (CEC), 2011 IEEE Congress on, Vol.14. pp.2633,2640, 5-8 June 2011.

[97] Zwe-Lee Gaing, "Constrained Dynamic Economic Dispatch Solution using Particle Swarm Optimization," Power Engineering Society General Meeting, 2004. IEEE, pp. 153158 Vol.1, 2004.

[98] Hardiansyah, Junaidi, and Yohannes MS"Solving Economic Load Dispatch Problem Using Particle Swarm Optimization Technique" I.J. Intelligent Systems and Applications, pp 1218,2012 .

[99] Niknam, T.; Golestane, F.; Bahmanifirouzi, B., "Modified adaptive PSO algorithm to solve dynamic economic dispatch," Power Engineering and Automation Conference (PEAM), 2011 IEEE, Vol.1, No.10, pp.108,111, 8-9 Sept. 2011.

[100] Divya Mathur "New Methodology for Solving Different Economic Dispatch Problems" International Journal of Engineering Science and Innovative Technology (IJESIT) Vol.2, No.1, pp.494-498 January 2013.

[101] C.K. Panigrahi, P.K. Chattopadhyay, R.N. Chakrabarti and M. Basu, "Simulated Annealing Technique for Dynamic Economic Dispatch," Electric Power Components and Systems, Vol. 34, No. 5, pp. 577-587, 2006.
[102] X.S. Han, H.B. Gooi and D.S. Kirschen, "Dynamic Economic Dispatch: Feasible and Optimal Solutions," Power Engineering Society Summer Meeting, 2001.IEEE, Vol.3, pp. 1704-1710, 2001.

[103] W. Ongsakul and J. Tippayachai, "Parallel Micro Genetic Algorithm Based on Merit Order Loading Solutions for Constrained Dynamic Economic Dispatch," Electrical Power Systems. Res., Vol. 61, no. 2, pp. 77-88, 2002.

[104]X. Yuan, L. Wang, Y. Zhang and Y. Yuan, "A Hybrid Differential Evolution Method for Dynamic Economic Dispatch with Valve-Point Effects," Expert Systems. Application, Vol. 36, no. 2, Part 2, pp. 4042-4048, 2009.

[105] M. Basu, "Artificial Immune System for Dynamic Economic Dispatch," International Journal of Electrical Power \& Energy Systems, Vol. 33, No. 1, pp. 131-136, 2011.

[106] S. Hemamalini and S.P. Simon, "Dynamic Economic Dispatch using Artificial Immune System for Units with Valve-Point Effect,"International Journal of Electrical Power \& Energy Systems, Vol. In Press, Corrected Proof, pp. 1-7,2011.

[107] Niknam, T.; Azizipanah-Abarghooee, R.; Aghaei, J., "A new modified teaching-learning algorithm for reserve constrained dynamic economic dispatch," Power Systems, IEEE Transactions on, Vol.28, No.2, pp.749, 763, May 2013.

[108] Rabiee, A; Mohammadi-Ivatloo, B.; Moradi-Dalvand, M., "Fast Dynamic Economic Power Dispatch Problems Solution Via Optimality Condition Decomposition," Power Systems, IEEE Transactions on, Vol.29, No.2, pp.982,983, March 2014.

[109] C.B. Somuah and N. Khunaizi, "Application of Linear Programming Dispatch Technique to Dynamic Generation Allocation," Power Systems, IEEE Transactions on, Vol. 5, No. 1, pp. 20-26, 1990.

[110] X.S. Han, H.B. Gooi and D.S. Kirschen, "Dynamic Economic Dispatch: Feasible and Optimal Solutions," Power Engineering Society Summer Meeting, 2001.IEEE, Vol.3, pp. 1704-1710, 2001.

[111] W. Lin and S. Chen, "Bid-Based Dynamic Economic Dispatch with an Efficient Interior Point Algorithm," International Journal of Electrical Power \& Energy Systems, Vol. 24, No. 1, pp. 51-57, 2002.

[112] W. Ongsakul and N. Ruangpayoongsak, "Constrained Dynamic Economic Dispatch by Simulated annealing/genetic Algorithms,"Power Industry Computer Applications, 2001. PICA 2001. Innovative Computing for Power - Electric Energy Meets the Market. 22nd IEEE Power Engineering Society International Conference on, pp. 207-212, 2001.

[113] T.A.A. Victoire and A.E. Jeyakumar, "Reserve Constrained Dynamic Dispatch of Units with Valve-Point Effects," Power Systems, IEEE Transactions on, Vol. 20, No. 3, pp. 1273-1282, 2005.

[114] T.A.A. Victoire and A.E. Jeyakumar, "A Modified Hybrid EP_ SQP Approach for Dynamic Dispatch with Valve-Point Effect," International Journal of Electrical Power \& Energy Systems, Vol. 27, No. 8, pp. 594-601, 2005.

[115] T.A.A. Victoire and A.E. Jeyakumar, "Deterministically Guided PSO for Dynamic Dispatch Considering Valve-Point Effect," Electrical Power Systems. Res., Vol. 73, No. 3, pp. 313-322, 2005. 
[116]F. Li, R. Morgan and D. Williams, "Hybrid Genetic Approaches to Ramping Rate Constrained Dynamic Economic Dispatch," Electrical. Power Systems. Res., Vol. 43, No.2, pp. 97-103, 1997.

[117] F. Li and R.K. Aggarwal, "Fast and Accurate Power Dispatch using a Relaxed Genetic Algorithm and a Local Gradient Technique," Expert Systems Application, Vol. 19,No. 3, pp. $159-165,2000$.

[118] P. Attaviriyanupap, H. Kita, E. Tanaka and J. Hasegawa, "A Hybrid EP and SQP for Dynamic Economic Dispatch with Non smooth Fuel Cost Function," Power Systems, IEEE Transactions on, Vol. 17, No. 2, pp. 411-416, 2002.

[119] Zwe-Lee Gaing and Ting-Chia Ou, "Dynamic Economic Dispatch Solution using Fast Evolutionary Programming with Swarm Direction," Industrial Electronics and Applications, 2009. ICIEA 2009. 4th IEEE Conference on, pp. 1538-1544, 2009.

[120] Y. Lu, J. Zhou, H. Qin, Y. Li and Y. Zhang, "An Adaptive Hybrid Differential Evolution Algorithm for Dynamic Economic Dispatch with Valve-Point Effects, "Expert Systems. Application, Vol. In Press, Accepted Manuscript, 2009.

[121] F. Kappel and A.V. Kuntsevich, "An Implementation of Shor's r-Algorithm,"Computational Optimization and Applications, Vol. 15, no. 2, pp. 193-205, 2000.

[122] V. Ravi Kumar Pandi and B.K. Panigrahi, "Dynamic Economic Load Dispatch using Hybrid Swarm Intelligence Based Harmony Search Algorithm," Expert Systems Applications, Vol. In Press, Corrected Proof, pp. 1-6, 2011.

[123] S. Sivasubramani and K.S. Swarup, "Hybrid SOA-SQP Algorithm for Dynamic Economic Dispatch with Valve-Point Effects," IEEE Transactions on Energy Conversion, Vol. 35, No. 12, pp. 5031-5036, 2010.

[124] A. M. Elaiw, X. Xia,and A. M. Shehata "Dynamic Economic Dispatch Using Hybrid DE-SQP for Generating Units with Valve-Point Effects" Hindawi Publishing Corporation Mathematical Problems in Engineering Vol. 20,pp 1-10,2012.

[125] Guoli Zhang, Hai Yan Lu, Gengyin Li and Hong Xie, "A New Hybrid Real-Coded Genetic Algorithm and Application in Dynamic Economic Dispatch, "Intelligent Control and Automation, 2006. WCICA 2006. The Sixth World Congess on, Vol.1, pp. 3627-3632, 2006.

[126] Dun-wei Gong et al "Environmental/economic power dispatch using a hybrid multi-objective optimization algorithm" IEEE Electrical Power and Energy Systems Vol. 32 pp 607614,2013 .
[127] Niknam, T.; Azizipanah-Abarghooee, R.; Roosta, A, "Reserve Constrained Dynamic Economic Dispatch: A New Fast SelfAdaptive Modified Firefly Algorithm," Systems Journal, IEEE, Vol.6, No.4, pp.635, 646, Dec. 2012.

[128] H. Shayeghi and A. Ghasemi "Application of MOPSO for Economic Load Dispatch Solution with Transmission Losses" International Journal on Technical and Physical Problems of Engineering (IJTPE), Vol 4 No.1, Issue 10 pp. 27-34, 2012.

[129] Hardiansyah "Solving Economic Dispatch Problem with Valve-Point Effect using a Modified ABC Algorithm" International Journal of Electrical and Computer Engineering (IJECE) Vol. 3, No. 3, pp. 377-385 June 2013.

[130] V.Karthikeyan S.Senthilkumar and V.J.Vijayalakshmi "A New Approach to the Solution of Economic Dispatch using Particle Swarm Optimization with Simulated Annealing" International Journal on Computational Sciences \& Applications (IJCSA) Vol.3, No.3,pp 37-49 June 2013.

[131] P. Attaviriyanupap, H. Kita, E. Tanaka and J. Hasegawa, "A Fuzzy-Optimization Approach to Dynamic Economic Dispatch Considering Uncertainties, "Power Systems, IEEE Transactions on, Vol. 19, No. 3, pp. 1299-1307, 2004.

[132] Y. Lu, J. Zhou, H. Qin, Y. Wang and Y. Zhang, "Chaotic Differential Evolution Methods for Dynamic Economic Dispatch with Valve-Point Effects," Engineering Application of Artificial Intelligence, Vol. 24, No. 2, pp. 378-387, 2011.

[133] S. Titus and A.E. Jeyakumar, "A Hybrid EP-PSO-SQP Algorithm for Dynamic Dispatch Considering Prohibited Operating Zones," Electric Power Components and Systems, Vol. 36, No. 5, pp. 449-467, 2008.

[134] P. Praveena, K. Vaisakh and S. Rama Mohana Rao, "A Bacterial Foraging PSODE Algorithm for Solving Dynamic Economic Dispatch Problem with Security Constraints," in Power Electronics, Drives and Energy Systems (PEDES) \& 2010 Power India, 2010 Joint International Conference on, pp. $1-7,2010$.

[135] A. A. Mousa et al "A Hybrid Optimization Technique Coupling an Evolutionary and a Local Search Algorithm for Economic Emission Load Dispatch Problem "Journal of Applied Mathematics, Vol.2, pp. 90-898,2011.

[136] Wang, M.Q.; Gooi, H.B.; Chen, S.X.; Lu, S., "A Mixed Integer Quadratic Programming for Dynamic Economic Dispatch With Valve Point Effect," Power Systems, IEEE Transactions on, Vol.29, No.5, pp.2097,2106, Sept. 2014. 